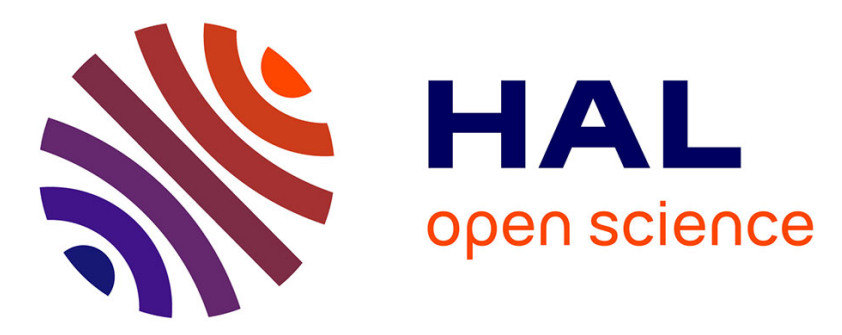

\title{
Improved frequency Resolution DFT Eases Teaching FFT Analysis and Provides better Amplitude Accuracy
}

\author{
Jean-Pierre Keradec, Xavier Margueron
}

\section{To cite this version:}

Jean-Pierre Keradec, Xavier Margueron. Improved frequency Resolution DFT Eases Teaching FFT Analysis and Provides better Amplitude Accuracy. IEEE IMTC 05, May 2005, Ottawa, Canada. pp.5395. hal-00182609

\section{HAL Id: hal-00182609 https://hal.science/hal-00182609}

Submitted on 12 Feb 2009

HAL is a multi-disciplinary open access archive for the deposit and dissemination of scientific research documents, whether they are published or not. The documents may come from teaching and research institutions in France or abroad, or from public or private research centers.
L'archive ouverte pluridisciplinaire HAL, est destinée au dépôt et à la diffusion de documents scientifiques de niveau recherche, publiés ou non, émanant des établissements d'enseignement et de recherche français ou étrangers, des laboratoires publics ou privés. 


\author{
Improved Frequency Resolution DFT Eases Teaching FFT Analysis \\ and Provides Better Amplitude Accuracy \\ Jean Pierre Keradec, Member IEEE, Xavier Margueron \\ Laboratoire d'Electrotechnique de Grenoble \\ INPG/UJF UMR-CNRS 5529, ENSIEG, B. P. 46 \\ 38402 Saint-Martiñ-d'Hères Cedex France \\ Phone: +33476826401 , Fax: +334768263 00, Email: keradec@1eg.ensieg.inpg.fr
}

\begin{abstract}
For a signal extension $T, D F T$ and FFT calculate the transform at frequencies $1 / 1$ apart. Due to this, amplitude of the transform can show more than $36 \%$ of discrepancy relatively to exact analytical Fourier Transform and this disagreement looks random. Calculating the transform with a frequency resolution 7 times thinner lowers this difference to within $1 \%$. As a result, obtained spectrums are easier to explain. This high resolution spectrum can be obtained either directly from time file or by interpolating frequency file that results from standard calculation. Both algorithms are supplied and spectrums of simple signals, obtained with standard and improved resolution, are compared.
\end{abstract}

Keywords - Fourier Transform, DFT calculation, high resolution spectrum, student experimentation.

\section{INTRODUCTION}

Spectrum analysis is among the most powerful tools engineers have at their disposal. Despite high performance spectrum analyzers are available, having to calculate the spectrum of a signal defined by a finite set of signal samples remains frequent. For example, the signal can be either an experimental one acquired by a numerical oscilloscope or a simulated one extracted from electronic simulation software such as Pspice@ [1]. In such a case the standard algorithm proposed for spectrum computation relies on Fast Fourier Transform (FFT) [2]. This algorithm is now often embedded in cheap numerical oscilloscope and it is also included in the tool box of most electronic simulation software.

For a qualitative study, FFT work fine but the judgment is not as good when quantitative results are expected. Even for a simple sinusoidal signal, calculated amplitude is between the expected one and $2 / \pi$ times this value, depending of the signal frequency. This put the student in trouble when he tries to explain the results. Using a longer record to achieve a thinner resolution is not always possible (memory length of oscilloscope is fixed) and, even if it was possible, frequencies should be better located, but amplitude should not be more accurate because accuracy is linked to the product "record time by frequency step" which remains equal to one. Windowing [3] does not bring an adequate solution to the evocated problem because it increases the difficulty of explaining the spectrum amplitude. However, this technique remains useful and compatible with the presented calculation.

Originally, FFT algorithm was developed to face the narrow memory space of available computers and the frequency step was chosen according to the "incertitude principle". It seemed that frequency resolution should not be increased by choosing a narrower step. Nothing else justifies this choice and impact on spectrum amplitude has not been taken into account.

In this paper we first recall the standard Discrete Fourier Transform (DFT) calculation and then we present an elementary calculation of the DFT using Mathcad software [4]. Supplicd algorithm applies whatever the number of signal samples is but, when this number is an integer power of two, it gives to the same result than FFT does. Improved frequency resolution DFT (IFR-DFT) algorithm is given simultaneously because it is very close to the former. Despite specd is not optimized, for 1000 values of signal, the result is obtained, with a common PC of 2005 , in about $2 \mathrm{~s}$ for standard resolution and $15 \mathrm{~s}$ for a 10 times thinner resolution. This allows students to experiment a lot.

This work is dedicated to 20 years old students learning electrical engineering. Several examples involving common electronic waveforms are given with an explanation intended for them. Waveforms are supposed acquired with a 1000 samples oscilloscope when less than 10 periods are visible on its screen.

\section{CALCULATIONS OF STANDARD AND IMPROVED RESOLUTION DFT}

Basically, DFT calculation (Table 1) start from Fourier Transform integral and it relies on following assumptions. Input signal is periodically sampled and it is known during a finite time T. During that time, it is defined by $\mathrm{N}$ samples $\mathbf{s}_{\mathrm{n}}$ so sampling interval is equal to $\mathrm{T} / \mathrm{N}$. Transform is evaluated at frequencies ranging from 0 to $\mathrm{N} / \overline{2} \mathrm{~T}$ which are $1 / \mathrm{T}$ apart.

In the improved resolution calculation, frequency covers the same range but previous frequency step is divided by integer $Q$ (Table 1). Function modulo is used to take advantage of the periodicity of complex exponential function.

This calculation is carried out after having defined a time function $s(t)$ and its $N$ samples: $s_{n}=s(n$ Te) and, its result is plot according to frequency: $i_{m}=\mathrm{m} / \mathrm{T}$ lor standard resolution and $f_{p}=m /(Q T)$ for improved resolution.

Values of the $\overline{D F T}$ are given from 0 to fe/2 (standard frequency range). Due to complex symmetry and periodicity of this function of frequency, its value for every other frequency can be deduced directly from one of the computed 
ones. This conclusion applies to $\overline{\mathrm{IFR}} \overline{\mathrm{DFT}}$ which also owns both properties of symmetry and periodicity.

\begin{tabular}{|l|l|}
\hline $\begin{array}{l}\mathrm{m}:=0 . . \mathrm{N}-1 \\
\Delta \mathrm{f}:=\frac{1}{\mathrm{~T}}\end{array}$ & $\begin{array}{l}\mathrm{Q}:=1 \mathrm{C} \\
\mathrm{p}:=0 . \mathrm{Q} \cdot \mathrm{N}-1 \\
\mathrm{Afa}:=\frac{\Delta \mathrm{f}}{\mathrm{Q}}\end{array}$ \\
$\mathrm{E}_{\mathrm{m}}:=\mathrm{e}$ & $-\mathrm{i} \frac{2 \cdot \pi}{\mathrm{N}} \cdot \mathrm{m}$ \\
$\mathrm{s}_{\mathrm{m}}:=\frac{\mathrm{T}}{\mathrm{N}} \sum_{\mathrm{n}=0}^{\mathrm{N}-1} \mathrm{~s}_{\mathrm{n}} \cdot \mathrm{E}_{\bmod (\mathrm{m} \cdot \mathrm{n}, \mathrm{N})} \cdot \mathrm{p}$ & $\mathrm{Sa}_{\mathrm{p}}:=\frac{\mathrm{T}}{\mathrm{N}} \sum_{\mathrm{n}=0}^{\mathrm{N}-1} \mathrm{~s}_{\mathrm{n}} \cdot \mathrm{Ea}_{\bmod (\mathrm{p} \cdot \mathrm{n}, \mathrm{Q} \cdot \mathrm{N})}$ \\
\hline $\begin{array}{l}\text { DFT with standard } \\
\text { resolution }\end{array}$ & $\begin{array}{l}\text { IFR-DFT with resolution } \\
\text { improved by a Q }=10 \text { ratio. }\end{array}$ \\
\hline
\end{tabular}

Table 1. DFT and IFR-DFT algorithm.

Despite studied transforms give real and imaginary parts, in this paper, focus will be on modulus that we will simply name "spectrum".

All signals considered in this paper are assumed to be known from $\mathrm{t}=0$ to $\mathrm{t}=1 \mathrm{~ms}$ and sampled at $\mathrm{fs}=1 \mathrm{Milz}$ so standard frequency range extends from 0 to $500 \mathrm{kHz}(=\mathrm{fs} / 2)$.

\section{CALCULATED SPECTRUM OF SNNUSOIDAL FUNCTIONS}

With this elementary waveform, results are easy to check. Its frequency $f$ is chosen close to $50 \mathrm{kHz}$ and its amplitude is equal to 1.

Because computation algorithm is easy to modify, computing spectrum over an extended frequency range is quickly carried out. Figure 1a shows the spectrum of a $50 \mathrm{kHz}$ sinus in the $0-2.1 \mathrm{MHz}$ range. Considering $\mathrm{fs}=1 \mathrm{MHz}$, figure $1 \mathrm{a}$ shows frequencies at $\mathrm{m} . \mathrm{Fs} \pm \mathrm{f}$. This allows verifying DFT periodicity and, for a real signal, that spectrum is even relatively to frequency. Maximum amplitude $\left(5.10^{-4}\right)$ is consistent with its theoretical value: exponential magnitude $(.5$ for sine amplitude $=1)$ multiplied by acquisition time. In the following, all computations will be carried out in the standard frequency range.

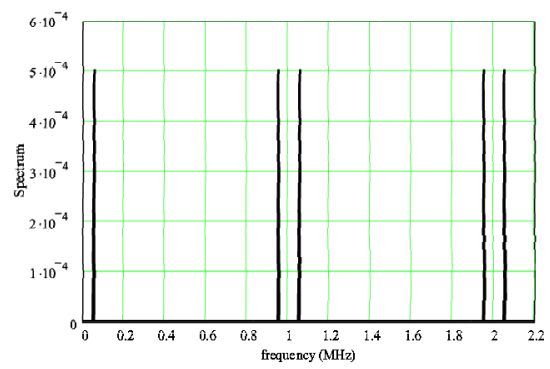

Figure 1. Spectrum, on an extended frequency range, of a $50 \mathrm{kHz}$ sinus, defined by 1000 samples taken at $1 \mathrm{MHz}$
Figure 2 zooms ( 45 to $5 \overline{5} \mathrm{kHz}$ ) on the $\overline{D F T}$ (dotted line) and the IFR-DFT (solid line) of the same signal. It clearly appears that standard calculation points are on the improved resolution calculation curve. Despite the effect of the natural (= rectangular) windowing is obvious with the improved resolution transform (modulus of a $\sin (x) / x$ function) it is not with the standard one. This important result cannot be observed with standard $\overline{D F T}$ or FFT algorithms.

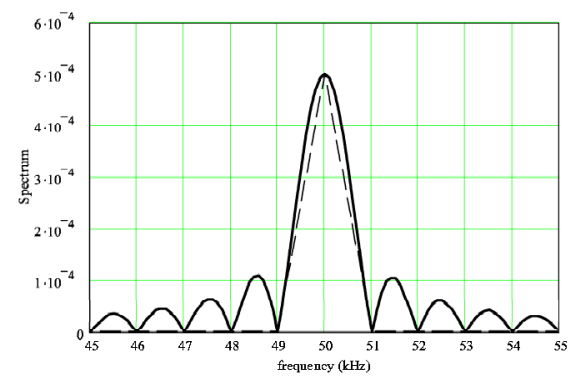

Figure ? Spectrum of a $50 \mathrm{kHz}$ sine wave, zoomed from 45 to $55 \mathrm{kHz}$. Dotted line DFT (resolution $1 \mathrm{kHz}$ ), solid line IFR-DFT (resolution $100 \mathrm{~Hz}$ )

Figure 3 shows the impact of a slight shift of signal frequency. Frequency equals $50.2 \mathrm{kLIz}$ for $3 a$ and $50.5 \mathrm{ki} \mathrm{Iz}$ for $3 b$. Despite the $\sin (x) / x$ curve is only shifted, modulus deduced from standard calculation varies because the transform is computed at frequencies which does not coincide with the maximunum of the cưrve. Here they are $1 \mathrm{kHz}$ aparat because signal is known during $1 \mathrm{~ms}$.

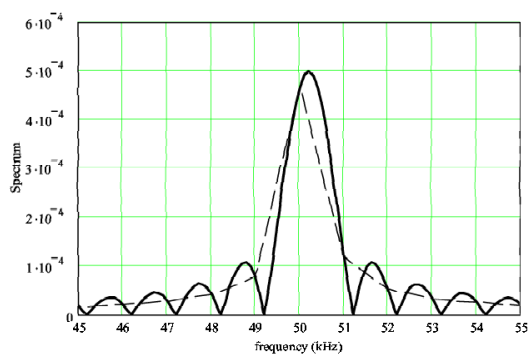

(a)

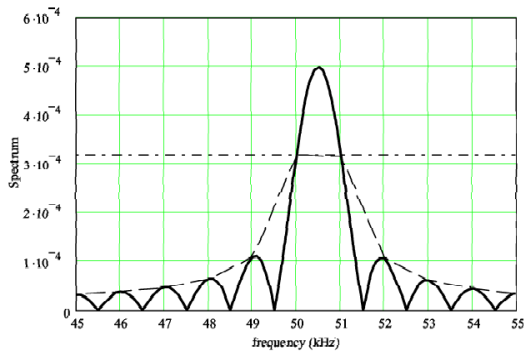

Figure 3. Spectrum of a $50.2 \mathrm{kHz}$ (a) and $50.5 \mathrm{kHz}$ (b) sine wave

With the standard resolution, for $50.5 \mathrm{kHz}$, the situation is at worst. Found amplitudes equal the $\max \sin (\mathrm{x}) / \mathrm{x}$ function value multiplied by $\sin (\varphi) / \varphi$ with $\varphi=\pi / 2$. This shows that 
standard calculation leads to a $36 \%$ loss in amplitude. It is clear that, depending on the analyzed frequency, amplitude loss varies between 0 and $36 \%$, leading to a feeling of random that leaves students disappointed.

From the same $\sin (x) / x$ calculation, it follows that, if step frequency is at least 7 times narrower, error is within $1 \%$. We choose 8 for FFT $\left(8=2^{3}\right)$ and 10 for DFT (as shown here).

Owing to the clarity of obtained curves, some more subtle properties appear. For example, with frequencies close to $5 \mathrm{kHz}$, and a zoom between 0 and $10 \mathrm{kHz}$, curves look asymmetrical (Hig. 4). Notice that, for $5 \mathrm{kHz}$, standard representation looks symmetrical. This dissymmetry is due to the proximity of the negative frequency peak. For $4.5 \mathrm{kHz}$, zeros of the two curves coincide and so it is for their sum. For $4.75 \mathrm{kHz}$, the sum no longer shows zeros.

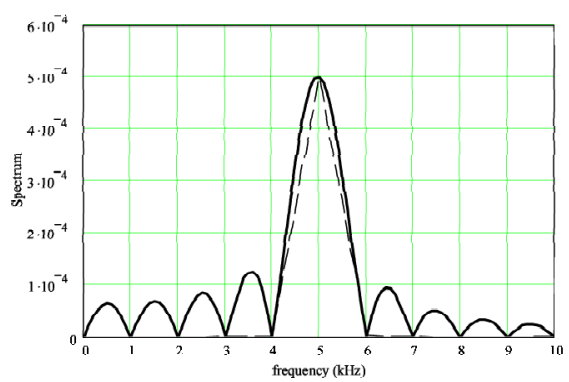

(a)

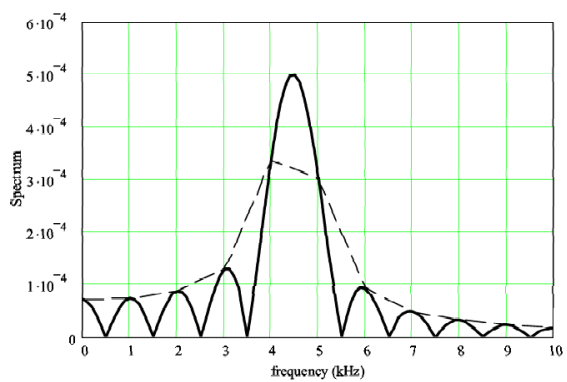

(b)

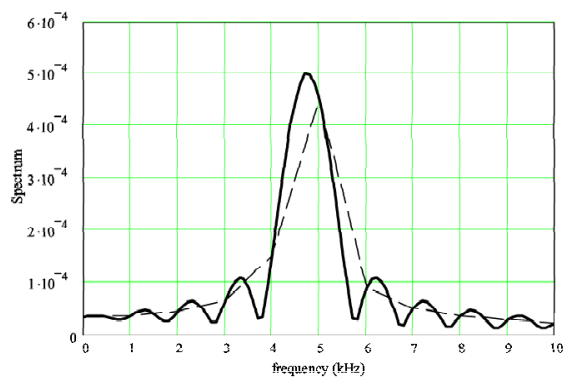

Figure 4. Spectrum of sinusoidal waveforms: $5 \mathrm{kHz}(\mathrm{a})$ $4.5 \mathrm{kHz}(\mathrm{b})$ and $4.75 \mathrm{kHz}$ (c)

\section{SPECTRUMS OF SQUARE FUNCTIONS}

Learning frequency analysis often begins by applying Fourier series to a square waveform. It is shown that, if cyclic ratio equals .5, even harmonics are null and harmonic amplitudes decrease as their order increase.

As shown in figure 4a, DFT results are consistent with these well established properties when square wave frequency is an integer multiple of the frequency step (1 kHz). In such a case, IFR-DFT performs as well but not better. Notice than, with Mathead, defining a square waveform c(t) having a null average value and a unit lundamental frequency amplitude is easily done as follows:

$$
\begin{aligned}
& \mathrm{a}:=\pi \cdot \frac{1-\eta}{\sin (\pi \cdot \eta)} \\
& \mathrm{c}(\mathrm{t}):=\mid \begin{array}{l}
\mathrm{a} \text { if }\left(\bmod \left(\frac{\mathrm{t}}{\mathrm{Ts}}, 1\right)<\eta\right) \\
\left(-\mathrm{a} \cdot \frac{\eta}{1-\eta}\right) \text { otherwise }
\end{array}
\end{aligned}
$$

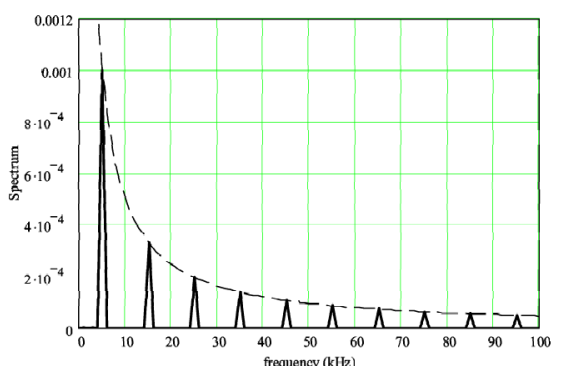

(a)

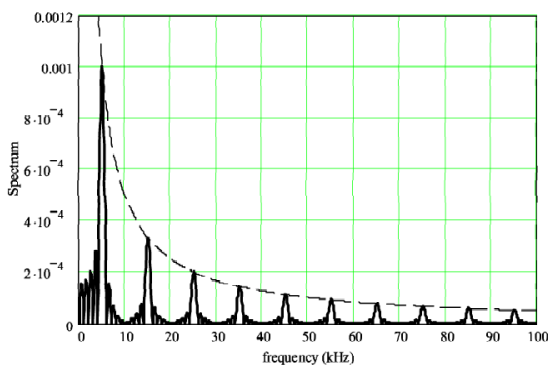

(b)

Figure 5 Spectrum of a $5 \mathrm{kHz}$, cyclic ratio 5 , square waveform. Calculated with (a) DFT, (b) IFR-DFT. Dotted line is the theoretical amplitude.

In practice, acquired signal frequency does not often respect the previous rule. Figure 5 shows that, for $5.167 \mathrm{kHz}$, DFT results looks random while those of IFR-DFT are more consistent. 

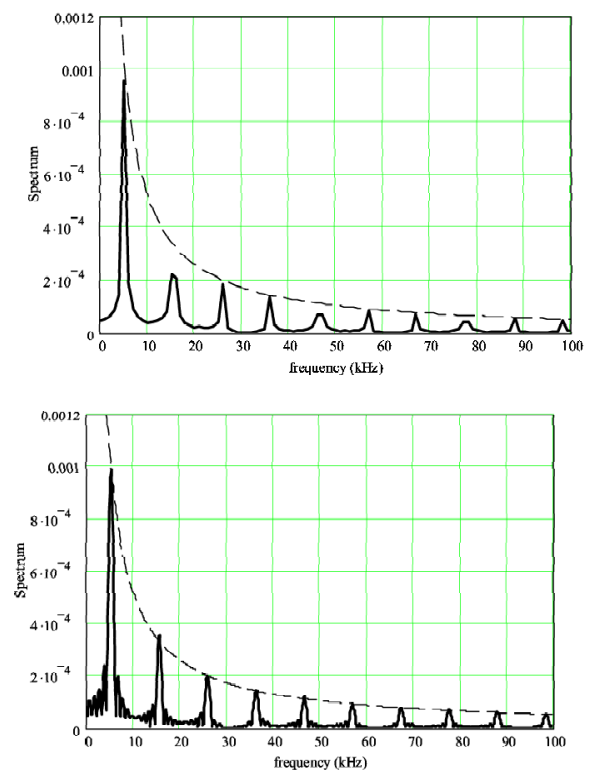

(a)

(b)

Figure 6. Spectrum of a $5.167 \mathrm{kHz}$, cyclic ratio .5 , square waveform. Calculated with (a) DFT, (b) IFR DFT.

Dotted line is the theoretical amplitude.

To go further, one shows that every periodic signal can be looked at as the convolution product of a Dirac's comb of the same frequency, by the waveform of one period only. The Fourier transform of this gives the simple product of the two mentioned function transforms. First one is a Dirac's comb of frequency which locates the lines of the spectrum while the second one gives their amplitudes. This way, finding amplitude variation of lines associated to a square wave with a cyclic ratio different from .5 is easy. Fourier transform of one period introduces a $\sin (\mathrm{x}) / \mathrm{x}$ function (Fig. 7 ).

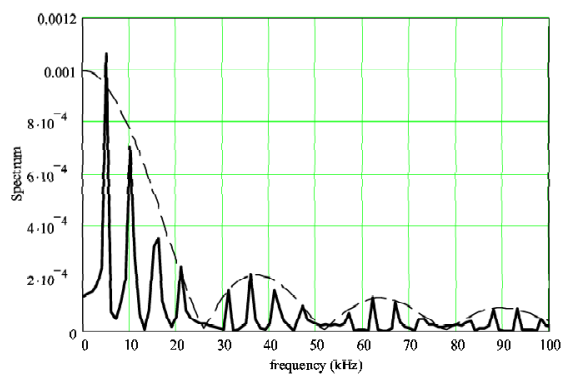

(a)

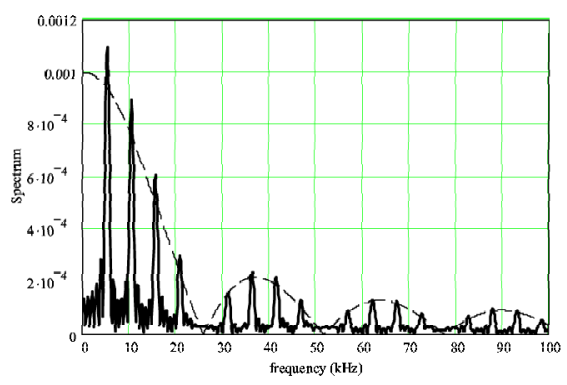

Figure 7 : Spectrum of a $5 \mathrm{kHz}$, cyclic ratio .2, square waveform. Calculated with (a) DFT, (b) IFP-DFT

\section{PRODUCTS OF PERIODIC FUNCTIONS}

Experimentally, following waveforms can be easily obtained using analog multiplier, analog gate or sample and hold.

First, product of sine wave (amplitude 2, frequency $5 \mathrm{kHz}$ ) by a square wave (minimum 0 , cyclic ratio . 1 , mean value 1 , frequency $50,167 \mathrm{kHz}$ ) is investigated. Theoretically, each line of the square wave is split into two lines of same magnitudes: first one is $5 \mathrm{kHz}$ below and second one $5 \mathrm{kHz}$ above the line of the square wave. According to what have been said about figure 7, line amplitudes of square wave decrease as $\sin (\mathrm{x}) / \mathrm{x}$ with a first zero at 10 times its frequency because cyclic ratio is now .1. Verification (Fig. 8) is quite obvious with IFR-DFT but not with DFT.

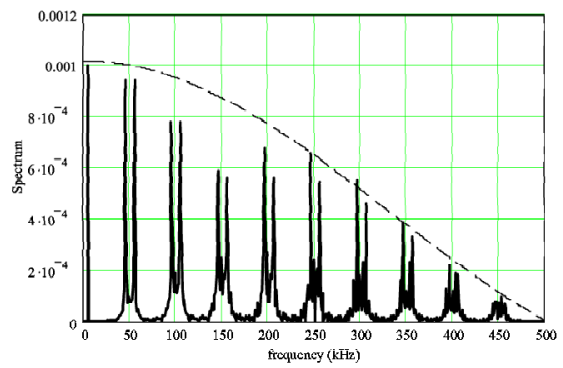

(a)

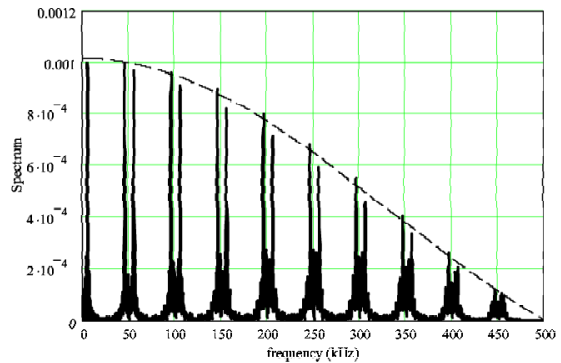

(b)

Figure 8. Spectrum of a $5.167 \mathrm{kHz}$, cyclic ratio .5 , square waveform. Calculated with (a) DFT, (b) IFR DFT. Dotted line is the theoretical amplitude.

Now, let us have a look to a sampled and hold sinus. This function (Fig. 9a) can be calculated as:

$$
f(t):=2 \cdot \sin \left(2 \cdot \pi \cdot f e \cdot T s \cdot \text { partentière }\left(\frac{t}{T_{s}}\right)\right)
$$

Where fe is the sine frequency and Ts the sampling period. Mathematically, this operation can be decomposed in two successive steps. First, the sine wave is sampled, that is to say it is multiplied by a Dirac's comb, then its goes through a blocking filter. First operation creates lines at m.fs $\pm \mathrm{fe}$ ( $\mathrm{fs}=1 / \mathrm{Ts}$ ) which all have the same amplitude. Blocking filter multiplies these amplitudes by its own gain which is proportional to $\sin (\mathrm{x}) / \mathrm{x}$ with first zero at fs. 
Figure 9 presents a $10.5 \mathrm{kHz}$ sinusoidal signal sampled and blocked at $100 \mathrm{kHz}$ with its spectrum. One more time, IFR-DFT is closer of theoretical curve than standard DFT.

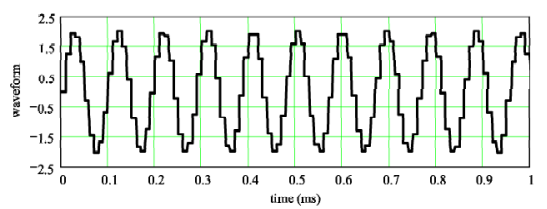

(a)

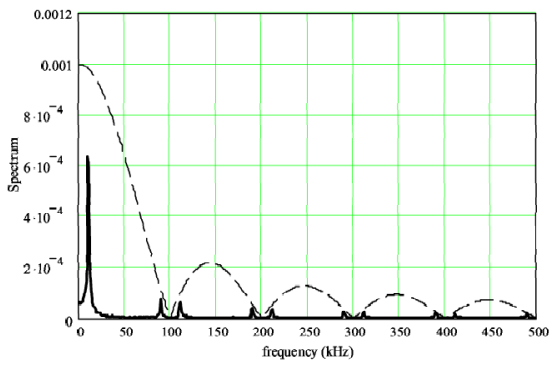

(b)

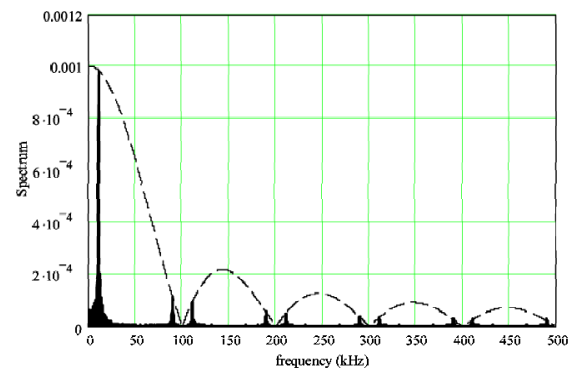

(c)

Figure $9.10 .5 \mathrm{kHz}$ sine wave sampled and hold at $100 \mathrm{kHz}$. Waveform (a), spectrum calculated with DFT (b), with IFR-DFT(c). Dotted line is the theoretical amplitude.

To end, most of sample and hold circuits allows a resistance $\mathrm{R}$ to be wired in parallel with the storage capacitor C. This disturbs the blocking function but not the sampling one. Figure 10a shows the resulting signal. It is composed of successive causal exponentials, the initial value of which equals the sine function. Notice that, due to the weak ratio $\tau / \mathrm{Ts}$, exponential heights seem not repetitive. As it is shown by figure $10 \mathrm{~b}$ and $\mathrm{c}$, lines are at same positions but their amplitudes are now consistent with a tirst order low pass filtering whose time constant is given by R C. Corresponding function is introduced as follows:

$$
\begin{aligned}
& \text { te }(\mathrm{t}):=\mathrm{Ts} \cdot \text { partentière }\left(\frac{\mathrm{t}}{\mathrm{Ts}}\right) \\
& \mathrm{s}(\mathrm{t}):=2 \cdot \sin (2 \cdot \pi \cdot \mathrm{fe} \cdot \mathrm{te}(\mathrm{t})) \\
& \mathrm{f}(\mathrm{t}):=\frac{\mathrm{Ts}}{\tau} \cdot \frac{\mathrm{s}(\mathrm{t})}{1-\exp \left(\frac{-\mathrm{Ts}}{\tau}\right)} \cdot \exp \left(-\frac{\mathrm{t}-\mathrm{te}(\mathrm{t})}{\tau}\right)
\end{aligned}
$$

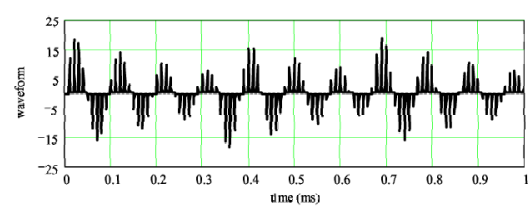

(a)

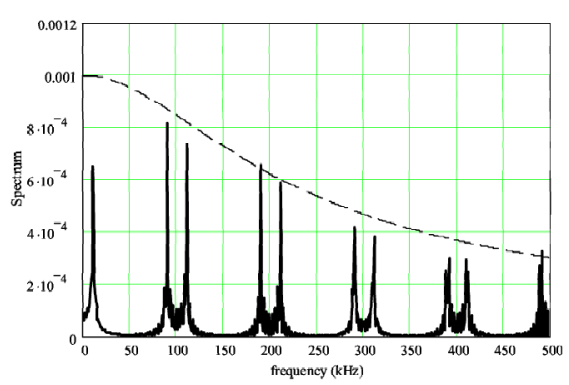

(b)

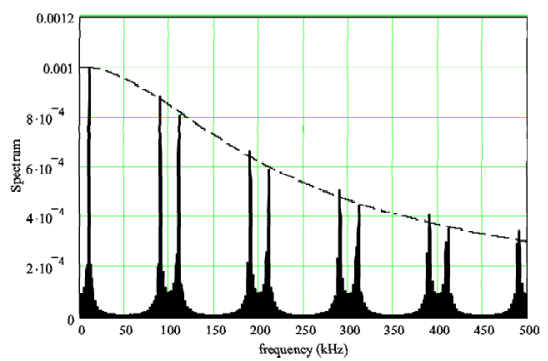

(c)

Figure 10. $10.5 \mathrm{kHz}$ sine wave sampled at $100,3 \mathrm{kHz}$. Waveform (a), spectrum calculated with DFT (b), with IFR-DFT(c). Dotted line is the theoretical amplitude.

In this case, adopted filtering is the Fourier transform of causal exponential function, that is to say, a first order low pass filiter. İts gain is written as :

$$
\frac{1}{\sqrt{1+(2 \cdot \pi \cdot \tau \cdot p \cdot \Delta f a)^{2}}}
$$

\section{CALCULÁTIONN BỸ INTERPPOLATIOON}

Because standard frequency resolution is fine enough to give back time samples, values of IFR-DFT can be deduced from those of standard DFT. This way, IFR-DFT appears as an interpolating algorithm. To reach this goal, we calculated time samples owing to inverse $\overline{D F T}$ before computing $\overline{\mathrm{IFR}}$ DFT. Found algorithm looks simpler if onc doubles exponential calculation interval (by periodicity). This is achieved by the first line of table 2 .

$$
\mathrm{Ea}_{\mathrm{p}+\mathrm{Q} \cdot \mathrm{N}}:=\mathrm{Ea}_{\mathrm{p}}
$$




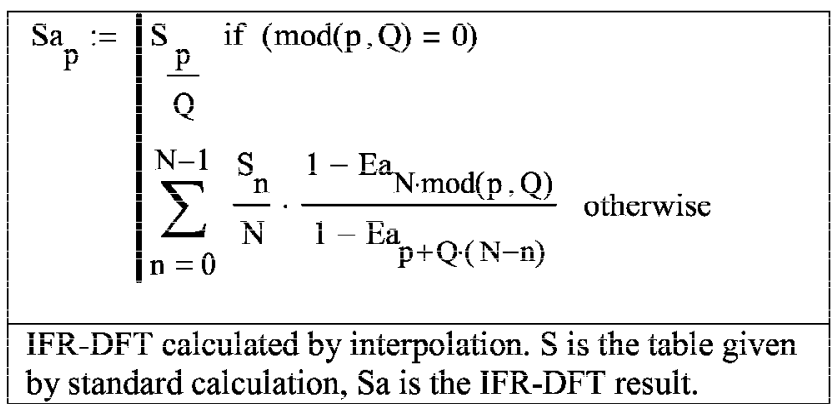

Table 2. IFR-DFT interpolation algorithm.

\section{VII.CONCLUSION}

It has been shown that standard calculations of both FFT and DFT lead to spectrum losses that can reach $36 \%$ according to the frequency of researched lines. This is due to the poor frequency resolütion which is âtways chosen in those algorithms. By choosing a frequency step at least 7 times smaller, this inaccuracy decreases to less than $1 \%$ and obtained curves becomes easier to understand. Modified calculation is simple and quite fast. It can start from either signal valües or standard transform values. In the second case, assuming real and imaginary parts of the transform are known, it computes an interpolation.

It could be a good idea to change FFT embedded in numerical oscilloscopes and other measuring apparatus to suppply the users with understandable spectrums. Same sūggestion applies for sūppliers of circuitit simūiation sofware.

Algorithms are given in Mathcad format so they can be easily used and modified by students, by teachers and, more widely, by spectrum analysis beginners who will find, in this paper, a lot of spectrum examples to think of. When computation speed matters, one can either generates a dll for Mathcad or write given algorithms in a compiled language such as $\mathbf{C}$.

\section{REFERENCES}

[1] Basic Circuit Ȧnalysis (2nd Edition) and Introduction to PSpice. John A. Stullcr, John Wilcy and Sons, 1995, ISBN 0-47-112733-7.

[2] The Fourier Transform and its Applications. Ronald N. Bracewell, Internationnal student edition 1978-McGraw-Hill 1965, ISBN 0-07007013-X.

[3] On the Use of Windows for Harmonic Analysis with the Discrete Fouricr Transform. Frederic I, Harris, Procecdings of the IEEE, vol. 66, $\mathrm{n}^{\circ} \mathbf{1}$, January $1 \hat{9} \bar{\jmath} \hat{8}$, pp. $5 \hat{1} \mathbf{1} \hat{8} \hat{3}$.

[4] Máthcad 11 1, Mathsoft Engineering and Education, İnc. 101 Main Strcet, Cambridge, MA 02142, USA. 